may have evolved unique ionic dependencies to cope with the diverse environments they encounter. Indeed, studies of bacterial carriers continue to provide surprising insights into neurotransmitter transporters, as illustrated by recent structural reports revealing the location of the antidepressantbinding site in a bacterial member of the SLC6 family ${ }^{10,11}$ _all in all a remarkable feat for organisms that don't even have a nervous system.
COMPETING INTERESTS STATEMENT

The author declares no competing financial interests.

1. Keynan, S. \& Kanner, B.I. Biochemistry 27, 12-17 (1988).

2. Torres, G.E., Gainetdinov, R.R. \& Caron, M.G. Nat. Rev. Neurosci. 4, 13-25 (2003).

3. Forrest, L.R., Tavoulari, S., Zhang, Y.W., Rudnick, G. \& Honig, B. Proc. Natl. Acad. Sci. USA 104, 12761-12766 (2007).

4. Zomot, E. et al. Nature, published online 19 August 2007 (doi:10.1038/nature06133).

5. Yamashita, A., Singh, S.K., Kawate, T., Jin, Y. \& Gouaux, E. Nature 437, 215-223 (2005).

6. Dutzler, R., Campbell, E.B.\& MacKinnon, R. Science
300, 108-112 (2003).

7. Dutzler, R., Campbell, E.B., Cadene, M., Chait, B.T \& MacKinnon, R. Nature 415, 287-294 (2002).

8. Ingram, S.L., Prasad, B.M. \& Amara, S.G. Nat. Neurosci. 5, 971-978 (2002).

9. Carvelli, L., McDonald, P.W., Blakely, R.D. \& Defelice, L.J. Proc. Natl. Acad. Sci. USA 101, 16046-16051 (2004).

10. Zhou, Z. et al. Science, published online 9 August 2007 (doi:10.1126/science1147614).

11. Singh, S.K., Yamashita, A. \& Gouaux, E. Nature, published online 8 August 2007 (doi:10.1038/nature06038).

12. Guex, N. and Peitsch, M.C. Electrophoresis 18 2714-2723 (1997).

\title{
X chromosome exposé
}

Drosophila melanogaster males, like males of a number of species, have only one $\mathrm{X}$ chromosome and thus only one copy of each $X$-linked gene-in contrast to females, who carry two copies of the $X$ chromosome. In humans, one copy in the female $\mathrm{X}$-chromosome pair is marked for silencing. Insects, including Drosophila, use the opposite solution: transcription on the single male $X$ chromosome is increased to attain expression comparable to that of the female $X$-linked genes, in a process called dosage compensation. Increased X-chromosome transcription in Drosophila has long been linked to a specific complex, the male-specific lethal (MSL) complex, containing five proteins as well as two noncoding RNAs, roX1 and roX2. How this complex is specifically targeted to a set of X-chromosomal genes and how it increases transcription remain somewhat obscure. The search for specific elements that bind male $\mathrm{X}$-linked genes and thus target them for ramped-up transcription has yielded short and degenerate sequences, and the MSL complex is known to bind at specific 'nucleating' points across the $\mathrm{X}$ chromosome. However, there is no sequence that clearly accounts for the widespread increase in transcription on just one chromosome. To add to the complexity, not all genes on the $\mathrm{X}$ chromosome are bound by the MSL complex. Kind and Akhtar have now provided evidence for a model where transcription of genes on the male $\mathrm{X}$ chromosome is crucial in targeting them for upregulation (Genes Dev.

21, 2030-2040, 2007).

The authors use a system where the X-chromosome genes mof and CG3016 have been inserted into an autosome. This removes the genes from the complex environment of the $\mathrm{X}$ chromosome itself, allowing features of the isolated genes to be assessed without influence or spreading of potential signals from neighboring $\mathrm{X}$-chromosomal regions. Fluorescence in situ hybridization studies examining the location of mof (pink in top panel) indicate that the MSL complex (green in bottom panel) still finds and binds the autosomally located gene (the new MSL-bound site, indicated by arrow, is at a locus distinct from that of the normal signal, which coats the entire $\mathrm{X}$ chromosome). Furthermore, chromatin immunoprecipitation assays examining several components of the MSL complex indicate that binding occurs across the coding region of the gene. Having developed a system where the gene is outside its normal context, the authors then altered the promoter and its activation status. The results support a model where promoter identity does not matter, as transcription of the gene can be driven by a promoter not found on the $\mathrm{X}$ chromosome, such as the tubulin promoter. However, the MSL complex binds only if

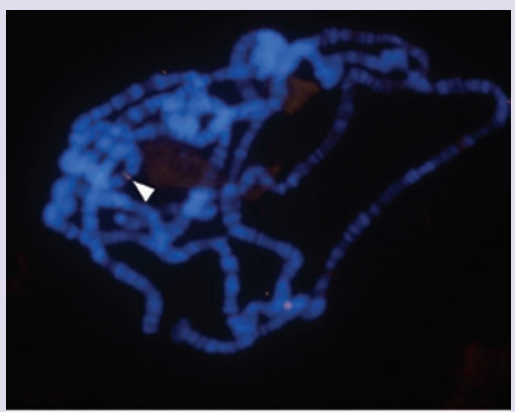
transcription is occurring through the gene itself, even if that transcription is being driven in an antisense direction. To further test the idea that transcription is essential, the authors treated cells with $\alpha$-amantin. When transcription is thus inhibited, MSL binding decreases not only at the mof locus, but across the entire $\mathrm{X}$ chromosome.

So why aren't all active genes susceptible to the MSL complex? The authors find that deletions near the $3^{\prime}$ end of the targeted gene prevent MSL binding, suggesting that dosage compensation depends on specific sequences embedded within the gene as well as on active transcription. However, these sequences are not, on their own, sufficient for MSL targeting unless present in multiple copies. Therefore the sequences can recruit the MSL complex only if present in the context of the gene itself. This leads to a model where transcription, and the passage of RNA polymerase II through the gene, 'reveal' the mof gene as a target, thus permitting the MSL complex to access its target sequences. The mechanism by which this occurs is currently unclear, but further studies may dissect changes in features such as chromatin structure in the gene or secondary structure in the nascent RNA important for MSL recruitment to its target. Such observations might show more clearly how transcription through a gene can expose a target site, ultimately allowing gene expression to be very specifically increased at certain loci. 